\title{
Optimal (Under-)Pricing and Allocation of Publicly Provided Goods
}

\author{
David Scrogin \\ University of Central Florida, Orlando, FL, USA \\ Email: dscrogin@ucf.edu
}

How to cite this paper: Scrogin, D. (2017) Optimal (Under-)Pricing and Allocation of Publicly Provided Goods. Theoretical Economics Letters, 7, 683-695.

https://doi.org/10.4236/tel.2017.74049

Received: February 25, 2017

Accepted: May 12, 2017

Published: May 15, 2017

Copyright (C) 2017 by author and Scientific Research Publishing Inc. This work is licensed under the Creative Commons Attribution International License (CC BY 4.0).

http://creativecommons.org/licenses/by/4.0/

\begin{abstract}
This paper exploits the links between a private value distribution's hazard rate, mean residual value, and eta functions in order to characterize postedprice rules for a public agency to allocate scarce units of an indivisible good under the utilitarian distributional objective of maximizing expected consumer surplus. Sufficient conditions on the monotonic and non-monotonic classes of the functions are established that identify either market assignment at the clearing price or lottery assignment with partial or complete underpricing as the optimal allocation mechanism. The results are summarized across a wide range of parametric value distributions, and selected non-monotonic cases are evaluated numerically to determine the relative scarcity or abundance of the good necessary for market or non-market assignment to dominate.
\end{abstract}

\section{Keywords}

Expected Consumer Surplus, Non-Market Mechanism, Lottery, Hazard Rate, Mean Residual Value

\section{Introduction}

Public agencies are commonly commissioned with allocating scarce units of indivisible goods and services over large numbers of individuals or households. Examples include assigning seats in schools, parcels of land and housing, access to medical services, immigration visas, and recreational privileges on publicly managed commons. An accompanying dilemma that agencies confront entails implementing an allocation mechanism to determine who will be awarded a unit and who will not. While expected revenues are maximized from allocating units by price or willingness to pay alone, agency objectives, laws and legislative mandates, or majority public preferences may lead agencies to deviate from competitive market assignment by under-pricing and allocating the units through a non- 
market mechanism, such as a lottery, queue or reservation system, or a merit or need-based assignment rule.

Several studies have investigated non-market allocation mechanisms in isolation and relative to market assignment or employed mechanism design to characterize optimal rules for allocating indivisible goods and services. In early work, [1] considered distributional and political economic aspects of rationing by queue, and [2] formalized a pseudo-market mechanism-the waiting-line auction-to characterize queuing behavior and equilibrium arrival times. [3] compared auctions, lotteries, and queues under deterministic demand and identified conditions for non-market assignment rules to be majority preferred. And [4] and [5] compared the expected efficiency of lotteries and queues under stochastic demand, whereby individual private valuations are drawn independently from a common distribution, and both concluded lotteries are superior if the good is relatively scarce and individual private values and time costs are sufficiently homogenous or negatively correlated.

In the mechanism design literature, [6] considered the case of two individuals with independent private valuations competing for a single unit of a good and demonstrated that expected net efficiency is maximized by random assignment if individuals incur sufficient signaling costs and the hazard rate of the distribution of individual private valuations is increasing. [7] also found random assignment to be optimal given an arbitrary number of ex ante identical individuals and a value distribution with an increasing hazard rate, whereas market assignment is optimal if sufficient screening costs are incurred by the agency and the hazard rate is decreasing. And [8] investigated the allocation problem when individual signaling costs are socially wasteful and the agency seeks to maximize expected social surplus. Consistent with [6] and [7], lottery assignment is shown to be optimal under certain conditions on individual types and the value distribution's hazard rate.

While the settings and approaches for investigating the market versus nonmarket assignment problem vary across the literature, the shape of the value distribution's hazard rate function (monotonic or non-monotonic) has consistently proven informative and critical to the conclusions. The tradition continues in this paper, where the links are exploited between the hazard rate function and its close counterparts-the mean residual life (or value) function and [9]'s eta function-in order to address the agency's mechanism choice problem under the distributional objective of maximizing aggregate expected consumer surplus $(E C S)^{1}$. From a symmetric independent private values framework it is shown that the optimal mechanism can be determined directly from the mean residual value function or indirectly from the hazard rate and eta functions, and suffi${ }^{1}$ For a given assignment of the good, consumer surplus is the difference between the sum of the private valuations of the recipients and the price each incurs for a unit of the good. Consumer surplus then appears in expectation because the agency is assumed to know the distribution of individual private valuations but not the valuation of any particular individual and because units of the good are allocated by lottery if price is set below the clearing rate. Further, as the price is posted by the agency prior to assigning the units, the randomness of consumer surplus over the set of possible assignments is not due to price uncertainty. 
cient conditions on each are established for market assignment or random (lottery) assignment with partial or complete under-pricing to be optimal ${ }^{2}$. The analysis extends results from [10]'s study of the effects of price controls on consumer surplus in competitive markets and demonstrates that maximizing ECS may be consistent with the agency achieving alternative objectives in allocating units of indivisible goods and services, such as maximizing revenues, net efficiency, or distributional equity. The results are summarized across a wide range of parametric distributions, and selected non-monotonic cases are evaluated numerically to determine the relative scarcity or abundance of the good necessary for market or non-market assignment to dominate.

\section{ECS Maximizing Allocation Rules}

\subsection{The Setting and Allocation Problem}

An agency holds $Q^{*}$ units of an indivisible good to be distributed over $N>Q^{*}$ individuals, where $N$ is assumed large and $Q^{*}$ may be small or large relative to $N$. Each individual possesses unit demand and a private valuation $v$ for the good that is independently drawn from the interval $[0, \infty)$ according to the distribution function $F(v)$ with density $f(v)=F^{\prime}(v) . Q^{*}, N$, and $F(v)$ are assumed commonly known, and each individual also knows his/her valuation but not the valuation of any other individual. Individual expected demand is then represented by the survival function $F^{*}(v)=1-F(v)$. That is, $F^{*}(v)$ is the probability an individual's valuation is at least $v$ or the probability the individual would be willing to purchase a unit if the price were $v$. Aggregate expected demand is $N F^{+}(v)$, and the expected market clearing price $v^{*}$ satisfies $N F^{*}(v)=Q^{*}$.

The agency's objective in allocating $Q^{*}$ is to maximize aggregate expected consumer surplus by posting a uniform price $p \in\left[0, v^{*}\right]$ and randomly assigning units if excess demand exists. Individual is expected probability of acquiring a unit conditional upon a valuation $v_{i} \in[p, \infty)$ is $\pi(p)=Q^{+} / N F^{+}(p)$ and $i s$ expected consumer surplus is written:

$$
\begin{aligned}
\operatorname{ECS}(p)_{i} & =\int_{p}^{\infty} \pi(p)(v-p) f(v) \mathrm{d} v \\
& =\frac{Q^{*}}{N F^{+}(p)}\left(\frac{1}{F^{+}(p)} \int_{p}^{\infty} v f(v) \mathrm{d} v-p\right) \quad \forall i \in N
\end{aligned}
$$

Aggregate expected consumer surplus the agency seeks to maximize is obtained by multiply (1) by expected demand, and the pricing problem is written:

$$
\max _{p} \operatorname{ECS}(p)=Q^{*}\left(\frac{1}{F^{+}(p)} \int_{p}^{\infty} v f(v) \mathrm{d} v-p\right)
$$

Given the value distribution and clearing price, the solution to (2) may be described by one of three mechanisms for allocating $Q^{*}$. These will be referred to as

${ }^{2}$ The hazard rate and eta function characterizations of the solution to the mechanism choice problem are appealing for evaluating particular value distributions (e.g., uniform, Pareto, Weibull, etc.) because unlike the mean residual value function, the hazard rate and eta functions commonly appear in closed form. 
market assignment at the clearing price $p=v$, pure lottery assignment at price $p$ $=0$, and hybrid lottery assignment at a price $p \in\left(0, v^{*}\right)$.

To proceed, note the term in brackets in (1) and (2) is the individual expected consumer surplus if a unit could be purchased outright for $p$. That is, it is the difference between a price $p$ and the individual mean private valuation conditional upon it being at least as large as $p$. The expression is the value distribution equivalent of a lifetime distribution's mean residual life function, defined $M R L(t)=\mathrm{E}[X-t \mid X \geq t]$. For a lifetime random variable $X, M R L(t)$ is the expected remaining life of the respective entity (e.g., a machine or individual) conditional upon its 'surviving' to time $t . M R L(t)$ is a close counterpart of the hazard rate function $H R(t)=f(t) / F^{+}(t)$ and [9]'s eta function $\eta(t)=-f^{\prime}(t) / f(t)$, and all are long-standing workhorses in the reliability engineering and stochastic ageing literature (see e.g., [11] and [12]). Denoting the value distribution's mean residual value function by $M R L(v)$ and its hazard rate and eta functions by $H R(v)$ and $\eta(v), E C S(p)$ in (2) is then the product of $Q^{*}$ and $M R L(v)$ evaluated at price $p=v$ for $v \in\left[0, v^{*}\right]$. That is, $\operatorname{ECS}(p)=Q^{*} M R L(p)$.

The relationship between $E C S(p)$ and $M R L(v)$ is appealing for characterizing the solution to (2) because the shape of $E C S(p)$ (monotonic or non-monotonic) is the same as that of $M R L(v)$ for $v \in\left[0, v^{*}\right]$ and because the shape of $M R L(v)$ is implied directly by $H R(V)$ and indirectly by $\eta(v)$ as shown by [9] [13] and [14] . Evaluation of $H R(v)$ or $\eta(v)$ may then be sufficient for determining the optimal allocation mechanism. The results are formalized for monotonic and non-monotonic classes of $M R L(v), H R(v)$, and $\eta(v)$ in the remainder of this section and selected cases are evaluated numerically in Section 3.

\subsection{Results}

In order to distinguish the monotonic and non-monotonic classes of $M R L(v)$ from one another, let IMRL (DMRL) denote $M R L(v)$ that is monotonic increasing (decreasing). That is, $M R L(v)$ is $I M R L(D M R L)$ if $M R L^{\prime \prime}(v)>0(<0)$ for $v \in$ $[0, \infty)$. For the non-monotonic classes, let DIMRL (IDMRL) denote the case in which $M R L(v)$ initially decreases (increases) to a minimum (maximum) at $v_{1} \in$ $(0, \infty)$ and then increases (decreases). That is, $M R L(V)$ is $D I M R L(I D M R L)$ if $M R L\left(v_{1}\right)=0, M R L^{\prime}(v)<0\left(M R L^{\prime}(v)>0\right)$ for $v<v_{1}$, and $M R L(v)>0\left(M R L^{\prime}(v)<\right.$ $0)$ for $v>v_{1}$. Further, as $M R L^{\prime}(v)=H R(v) M R L(v)-1$, it follows that at $M R L(v)$ 's interior minimum or maximum, $M R L\left(v_{1}\right)=1 / H R\left(v_{1}\right)$. The monotonic and nonmonotonic classes of $H R(v)$ and $\eta(v)$ will be similarly referenced below (e.g., $I H R$ and $D I H R)$.

Given $\operatorname{ECS}(p)=Q^{*} M R L(p)$ if $p=v$, it is clear that $\operatorname{ECS}(p)$ is maximized by market (pure lottery) assignment of $Q^{*}$ if $M R L(v)$ is $I M R L$ (DMRL). If instead $M R L(v)$ is non-monotonic, then $E C S(p)$ may or may not be monotonic for $p \in$ $\left[0, V^{*}\right)$ and information on the relative scarcity or abundance of the good is needed to determine the optimal mechanism directly from $M R L(v)$ or indirectly from $H R(v)$ and $\eta(v)$. To link $H R(v)$ and $E C S(p)$ through $M R L(v)$ the following ${ }^{3}$ Relations between $M R L(v), H R(v)$, and $\eta(v)$ can be seen by noting that $M R L(v)=H R(v) M R L(v)-$ 1, $M R L^{\prime}(v)=H R^{\prime}(v) M R L(v)+H R(v) M R L(v)$, and $H R^{\prime}(v)>/=/<0$ if $\eta(v)>/=/<1 / H R(v)$. 
sufficient conditions from [13] and [14] are used: ${ }^{4}$

i) If $H R(v)$ is $\operatorname{IHR}(D H R)$, then $M R L(v)$ is $D M R L$ (IMRL).

ii) If $H R(v)$ is $I D H R$ and $f(0) \mu<1(f(0) \mu \geq 1)$, then $M R L(v)$ is $D I M R L(I M R L)$.

iii) If $H R(v)$ is $D I H R$ and $f(0) \mu>1(f(0) \mu \leq 1)$, then $M R L(v)$ is IDMRL $(D M R L)$.

Monotonicity of $H R(v)$ therefore implies monotonicity of $M R L(v)$, whereas non-monotonicity $H R(v)$ may or may not imply non-monotonicity of $M R L(V)$. For linking $\eta(v)$ and $E C S(p)$ through $H R(v)$, sufficient conditions from [9] are used. Defining $\varepsilon$ and $\delta$, respectively, as $\lim _{v \rightarrow \infty} f(v)=\varepsilon$ and $\lim _{v \rightarrow \infty} \eta(v) / H R(v)=\delta$, the conditions are:

i) If $\eta(v)$ is $I(D)$, then $H R(v)$ is $\operatorname{IHR}(D H R)$.

ii) If $\eta(v)$ is $D I$ and $\varepsilon=0$ or $\delta<1(\varepsilon=\infty$ or $\delta>1)$, then $H R(V)$ is $\operatorname{IHR}(D I H R)$.

iii) If $\eta(V)$ is ID and $\varepsilon=0$ or $\delta<1(\varepsilon=\infty$ or $\delta>1)$, then $H R(v)$ is $\operatorname{IDHR}$ (DHR).

Monotonicity of $\eta(v)$ therefore implies monotonicity of $H R(v)$ and of $M R L(v)$ by transitivity, whereas if $\eta(v)$ is non-monotonic, then $H R(v)$ and $M R L(v)$ may or may not be non-monotonic. While the above conditions are used here for characterizing optimal allocation rules, they have proven invaluable for determining the shape of $M R L(t)$ in reliability engineering and stochastic ageing studies because $M R L(t)$ typically does not appear in closed form (see e.g., [11]).

The solution to (2) is given first in Proposition 1 and Corollary 1 for cases of $H R(v)$ and $\eta(v)$ that imply $M R L(v)$ that is monotonic, followed by the cases of non-monotonic $M R L(V)$ in Propositions 2 and 3.

Proposition 1: Given $Q^{*}, N$, and $F(v)$ :

i) If $H R(v)$ is $D H R(I H R)$, then $E C S(p)$ is maximized by market (pure lottery) assignment of $Q^{*}$.

ii) If $H R(v)$ is $I D H R$ and $\mu f(0) \geq 1(D I H R$ and $\mu f(0) \leq 1)$, then $E C S(p)$ is maximized by market (pure lottery) assignment of $Q^{*}$.

Proof: i) If $H R(v)$ is $D H R(I H R)$, then $M R L(v)$ is $I M R L(D M R L)$. Therefore, $E C S\left(\stackrel{*}{v}^{*}\right)>E C S(p)$ for $p \in\left[0, v^{*}\right)\left(E C S(0)>E C S(p)\right.$ for $\left.p \in\left(0, v^{*}\right]\right)$ and $E C S(p)$ is maximized by market (pure lottery) assignment of $Q^{*}$.

ii) If $H R(v)$ is $I D H R$ and $\mu f(0) \geq 1(D I H R$ and $\mu f(0) \leq 1)$, then $M R L(v)$ is $\operatorname{IMRL}(D M R L)$. Therefore, $\operatorname{ECS}\left(v^{*}\right)>\operatorname{ECS}(p)$ for $p \in\left[0, v^{*}\right)(E C S(0)>E C S(p)$ for $\left.p \in\left(0, V^{*}\right]\right)$ and $E C S(p)$ is maximized by market (pure lottery) assignment of $Q^{*}$.

Distributions for which Proposition 1 applies (and Propositions 2 and 3 below) are reported in Table 1 . If private values are Pareto distributed (see [10] for a detailed example) or exponential-geometric distributed, then $M R L(V)$ is $I M R L$ and $\operatorname{ECS}(p)$ is maximized by market assignment of $Q^{*}$, and if private values are uniform, truncated normal, or Gompertz-Makeham distributed, then $M R L(v)$ is $D M R L$ and $E C S(p)$ is maximized by allocating $Q^{*}$ by pure lottery. If instead values are Weibull or gamma distributed, then market or pure lottery assignment could be optimal as $M R L(V)$ is either IMRL or $D M R L$.

Corollary 1 follows immediately from Proposition 1 and [9]'s sufficient condi- 
Table 1. Allocation Mechanisms that Maximize $\operatorname{ECS}(p)$ for Parameteric Value Distributions ${ }^{\mathrm{a}}$.

\begin{tabular}{|c|c|c|c|c|c|c|c|}
\hline \multirow[b]{2}{*}{ Distribution (Proposition) } & \multicolumn{4}{|c|}{ Monotonicity of $H R(v)$} & \multicolumn{3}{|c|}{ Allocation Mechanism } \\
\hline & $D H R$ & $I H R$ & $D I H R$ & $I D H R$ & Market & Pure Lottery & Hybrid Lottery \\
\hline Exponential Geometric (1) & $\mathrm{X}$ & & & & $\mathrm{X}$ & & \\
\hline Gamma (1) & $\mathrm{X}$ & $\mathrm{x}$ & & & $\mathrm{X}$ & $\mathrm{X}$ & \\
\hline Gompertz-Makeham (1) & & $\mathrm{X}$ & & & & $\mathrm{X}$ & \\
\hline Pareto (1) & $\mathrm{X}$ & & & & $\mathrm{X}$ & & \\
\hline Truncated Normal (1) & & $\mathrm{X}$ & & & & $\mathrm{X}$ & \\
\hline Uniform (1) & & $\mathrm{X}$ & & & & $\mathrm{X}$ & \\
\hline Weibull (1) & $\mathrm{X}$ & $\mathrm{X}$ & & & $\mathrm{X}$ & $\mathrm{X}$ & \\
\hline Gumbel (2) & & & & $\mathrm{X}$ & $\mathrm{X}$ & $\mathrm{X}$ & \\
\hline Inverse Gaussian (2) & & & & $\mathrm{X}$ & $\mathrm{X}$ & $\mathrm{X}$ & \\
\hline Log-normal (2) & & & & $\mathrm{X}$ & $\mathrm{X}$ & $\mathrm{X}$ & \\
\hline Burr XII $(1,2)$ & $\mathrm{X}$ & & & $\mathrm{X}$ & $\mathrm{X}$ & $\mathrm{X}$ & \\
\hline $\log$-logistic $(1,2)$ & $\mathrm{X}$ & & & $\mathrm{X}$ & $\mathrm{X}$ & $\mathrm{X}$ & \\
\hline Beta $(1,3)$ & & $\mathrm{X}$ & $\mathrm{X}$ & & $\mathrm{X}$ & $\mathrm{X}$ & $\mathrm{X}$ \\
\hline Exponential Power $(1,3)$ & & $\mathrm{X}$ & $\mathrm{X}$ & & $\mathrm{X}$ & $\mathrm{X}$ & $\mathrm{X}$ \\
\hline Modified Weibull $(1,3)$ & & $\mathrm{X}$ & $\mathrm{X}$ & & $\mathrm{X}$ & $\mathrm{X}$ & $\mathrm{X}$ \\
\hline Weibull Extension $(1,3)$ & & $\mathrm{X}$ & $\mathrm{X}$ & & $\mathrm{X}$ & $\mathrm{X}$ & $\mathrm{X}$ \\
\hline Exponeniated Weibull $(1,2,3)$ & $\mathrm{X}$ & $\mathrm{X}$ & $\mathrm{X}$ & $\mathrm{X}$ & $\mathrm{X}$ & $\mathrm{X}$ & $\mathrm{X}$ \\
\hline Generalized Weibull $(1,2,3)$ & $\mathrm{X}$ & $\mathrm{X}$ & $\mathrm{X}$ & $\mathrm{X}$ & $\mathrm{X}$ & $\mathrm{X}$ & $\mathrm{X}$ \\
\hline
\end{tabular}

a The distributions and their properties are discussed in [11] [12] or [17].

tions on $\eta(v)$ discussed above.

Corollary 1: Given $Q^{*}, N$, and $F(v)$ :

i) If $\eta(v)$ is $D(I)$, then $E C S(p)$ is maximized by market (pure lottery) assignment of $Q^{*}$.

ii) If $\eta(v)$ is $D I(I D)$ and $\varepsilon=0$ or $\delta<1(\varepsilon=\infty$ or $\delta>1)$, then $E C S(p)$ is maximized by pure lottery (market) assignment of $Q^{*}$.

Proof: The results follow by transitivity from Proposition 1 and [9]'s sufficient conditions on $\eta(v)$ for $H R(v)$ to be $D H R$ or $I H R$, implying $M R L(v)$ is $I M R L$ or $D M R L$, respectively.

In the remaining cases, $H R(v)$ implies $M R L(v)$ is non-monotonic. A graphical depiction of $H R(v)$ and $M R L(v)$ that are $i) I D H R$ and $D I M R L$ and ii) DIHR and $I D M R L$ appear in Figure 1 and Figure 2, respectively. Included are $M R L(V)$ and $1 / H R(v)$. From Figure 1, if the clearing rate $v^{*}$ is such that $M R L\left(v^{*}\right)>M R L\left(v_{\mu}\right)=$ $\mu$, then $F^{+}\left(v^{*}\right)<F^{+}\left(v_{\mu}\right)$ and $E C S(p)$ is maximized by market assignment, and if $\operatorname{MRL}\left(\stackrel{v}{V}^{*}\right)<\operatorname{MRL}\left(v_{\mu}\right)=\mu$, then $F^{+}\left(v^{*}\right)>F^{\dagger}\left(v_{\mu}\right)$ and $E C S(p)$ is maximized by pure lottery assignment. From Figure 2, if $V^{*}>v_{1}$ then $M R L\left(V^{*}\right)<M R L\left(v_{1}\right), F^{*}\left(V^{*}\right)<$ $F^{+}\left(V_{1}\right)$, and $E C S(p)$ is maximized by allocating $Q^{*}$ by hybrid lottery at price $p=$ $V_{1}$; otherwise, market assignment of $Q^{*}$ is optimal. 


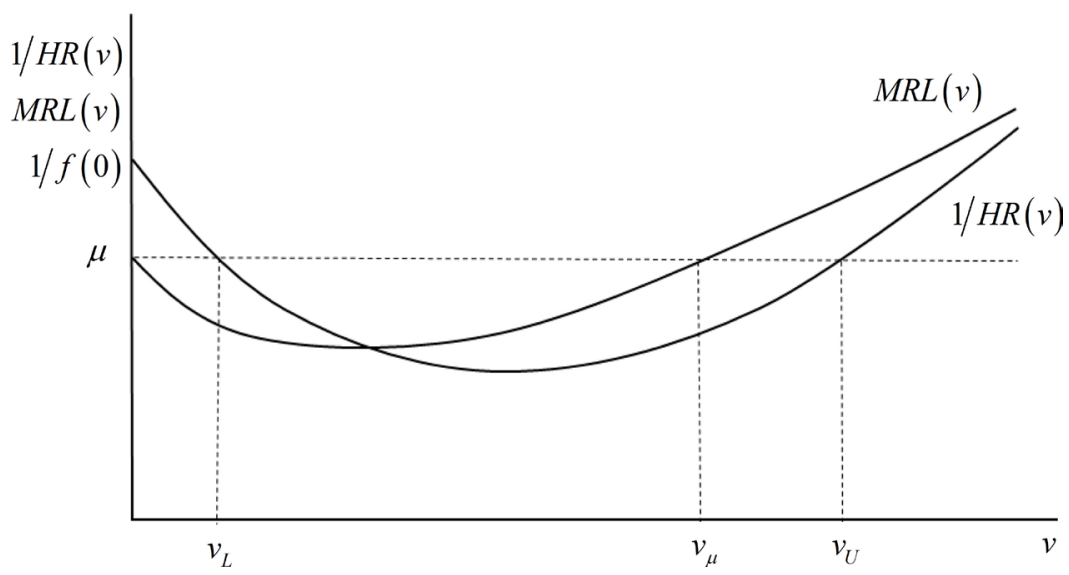

Figure 1. Example of Non-monotonic $H R(v)$ and $M R L(v)$ for Proposition 2.

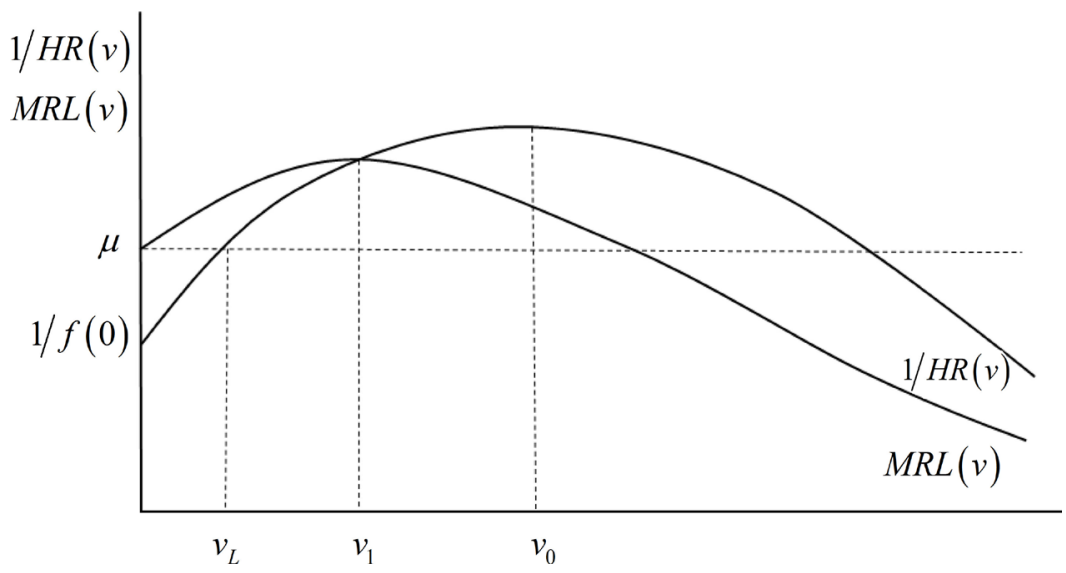

Figure 2. Example of Non-monotonic $H R(v)$ and $M R L(v)$ for Proposition 3.

Figure 1 and Figure 2 also indicate that the optimal mechanism can be determined from evaluation of $H R(v)$ and $\mu$ if ${ }_{v}^{*}$ is sufficiently scarce or abundant. The results are formalized in Proposition 2 for $H R(v)$ implying $D I M R L$ and in Proposition 3 for $H R(v)$ implying DIMRL.

Proposition 2: Given $H R(v)$ that is $I D H R$ and $\mu f(0)<1$ :

i) If $H R^{\prime}\left(v^{*}\right)>0$ and $1 / H R\left(v^{*}\right) \geq \mu$, then $E C S(p)$ is maximized by pure lottery assignment of $Q$.

ii) If $H R^{\prime \prime}\left(V^{*}\right)<0$ and $1 / H R\left(V^{*}\right) \geq \mu$, then $\operatorname{ECS}(p)$ is maximized by market assignment of $Q^{*}$.

iii) If $\lim _{v \rightarrow \infty} 1 / H R(v) \leq \mu$, then $E C S(p)$ is maximized by pure lottery assignment of $Q^{*}$.

Proof. In all cases, if $H R(v)$ is $I D H R$ and $\mu f(0)<1$, the $M R L(v)$ is $D I M R L$.

i) As $M R L^{\prime \prime}(v)<0$ if $H R^{\prime}(v)>0$ and $1 / H R(v) \geq \mu$, it follows that if $H R^{\prime \prime}\left(v^{*}\right)>0$ and $1 / H R\left(v^{*}\right) \geq \mu$, then $\mu>\operatorname{MRL}\left({ }^{*}\right)$. Therefore, $\operatorname{ECS}(0)>\operatorname{ECS}(p)$ for $p \in\left(0, v^{*}\right]$ and $E C S(p)$ is maximized by pure lottery assignment of $Q^{*}$.

ii) If $H R^{\prime}\left(V^{*}\right)<0$ and $1 / H R\left(V^{*}\right) \geq \mu$, then $M R L\left(V^{*}\right)>\mu$. It follows that $E C S\left(V^{*}\right)>$ $E C S(p)$ for $p \in\left[0, v^{*}\right)$ and $E C S(p)$ is maximized by market assignment of $Q^{*}$.

iii) From [16], $\lim _{v \rightarrow \infty} M R L(v)=\lim _{v \rightarrow \infty} 1 / H R(v)$ if the latter limit is finite. Therefore, 
$\lim _{v \rightarrow \infty} M R L(v) \leq \mu$ if $\lim _{v \rightarrow \infty} 1 / H R(v) \leq \mu$. It follows that $E C S(0)>E C S(p)$ for $p \in\left(0, v^{*}\right]$ and $E C S(p)$ is maximized by pure lottery assignment of $Q^{*}$.

Figure 1 depicts cases $i$ and $i$ ii of Proposition $2 .{ }^{5}$ Case $i$ applies to the lower interval $v \in\left[0, v_{L}\right]$. As $H R^{\prime}(v)>0$ and $1 / H R(v) \geq \mu$, it follows that $\mu>\operatorname{MRL}(v)$. Therefore, if $Q^{*}$ is sufficiently abundant such that $V^{*} \leq v_{L}$, then $\operatorname{ECS}(0)>\operatorname{ECS}\left(V^{*}\right)$, and $\operatorname{ECS}(p)$ is maximized by allocating $Q^{*}$ by pure lottery. For case $i$, as $H R^{\prime}(v)$ $<0$ and $1 / H R(v) \geq \mu$ in the upper interval $v \in\left[v_{U}, \infty\right)$, it follows that $M R L(v)>$ $\mu$. Therefore, if $Q^{*}$ is sufficiently scarce such that $v^{*} \geq v_{U}$ then $\operatorname{ECS}\left(v^{*}\right)>\operatorname{ECS}(0)$ and market assignment is optimal. Similar to Proposition 1, examples of distributions for which Proposition 2 applies are reported in Table 1. Included are the lognormal, inverse Gaussian, log-logistic, and Burr XII distributions and variants of the Weibull distribution.

Lastly, the case in which $H R(v)$ implies $M R L(v)$ that is $I D M R L$ is covered in Proposition 3.

Proposition 3: Given $H R(v)$ that is $D I H R$ and $\mu f(0)>1$ :

i) If $H R^{\prime}\left(V^{*}\right)<0$ and $1 / H R\left({ }^{*}\right) \leq \mu$, then $E C S(p)$ is maximized by market assignment of $Q^{*}$.

ii) If $H R^{\prime}\left(V^{*}\right) \geq 0$, then $\operatorname{ECS}(p)$ is maximized by hybrid lottery assignment of $Q^{*}$.

Proof: In both cases, if $H R(v)$ is $D I H R$ and $\mu f(0)>1$, then $M R L(v)$ is $I D M R L$.

i) If $H R^{\prime}\left(V^{*}\right)<0$ and $1 / H R\left(V^{*}\right) \leq \mu$, then $V^{*}<v_{1}$. As $Q^{*}>N F^{*}(v)$ for $v V^{*}$ and $\operatorname{MRL}(v)>0$ for $v<v_{1}$, it follows that $\operatorname{ECS}\left(v^{*}\right)>\operatorname{ECS}(p)$ for $p \in\left[0, v^{*}\right)$ and $E C S(p)$ is maximized by market assignment of $Q^{*}$.

ii) If $H R^{\prime}\left(v^{*}\right) \geq 0$, then $\stackrel{*}{v}^{*} v_{1}$ and $M R L(v)>M R L\left({ }^{*}\right)$ for $v \in\left[v_{1}, v^{*}\right)$. Therefore, $\operatorname{ECS}(p)>\operatorname{ECS}\left(V^{*}\right)$ for $p \in\left[v_{1}, V^{*}\right)$ and $E C S(p)$ is maximized by hybrid lottery assignment of $Q^{*}$.

Results from Proposition 3 are depicted in Figure 2. Case $i$ applies to the interval $v \in\left[0, v_{L}\right]$. As $H R^{\prime}(v)<0$ and $1 / H R(v) \leq \mu$ it follows that $M R L(v)>\mu$ and $\operatorname{MRL}(v)>0$. Therefore, if the scarcity of $Q^{*}$ is such that ${ }^{*} \leq v_{L}$, then $\operatorname{ECS}(0)<$ $\operatorname{ECS}\left(v^{*}\right)$, and $E C S(p)$ is maximized by selling $Q^{*}$ outright. For case $i$, as $M R L^{\prime}(v)$ $<0$ for $v \in\left(v_{1}, \infty\right)$, if $H R^{\prime}\left(v^{*}\right) \geq 0$ (or $v^{*} \geq v_{0}$ ) then $M R L\left(v_{0}\right) \geq M R L\left(v^{*}\right)$. It follows that $\operatorname{MRL}(v)>\operatorname{MRL}\left(V^{*}\right)$ for some values in the interval $\left(0, v^{*}\right)$. Therefore, if $Q^{*}$ is sufficiently abundant such that $V^{*} \geq v_{0}$, then $E C S(p)$ attainable from allocating $Q^{*}$ by hybrid lottery exceeds that from market assignment. Table 1 report several distributions for which Proposition 3 applies. Included are the beta and exponential power distributions and variants of the Weibull distribution.

\section{Numerical Examples}

As shown above, while the allocation mechanism that maximizes $\operatorname{ECS}(p)$ is independent of $Q^{*}$ if $M R L(v)$ is monotonic (Proposition 1), information on the relative scarcity or abundance of the good is needed to determine the optimal mechanism if $M R L(v)$ is non-monotonic (Propositions 2 and 3). To demonstrate, two of the distributions reported in Table 1 are evaluated numerically. In

${ }^{5}$ Case $i i i$ would appear in place of case $i i$ in Figure 1 if $\lim _{v \rightarrow \infty} 1 / H R(v) \leq \mu$. 
the first, private values are assumed log-logistic distributed. $M R L(v)$ is $D I M R L$ for certain parameter values and $E C S(p)$ is maximized either by market or pure lottery assignment (see Proposition 2 and Figure 1). In the second, private values are assumed beta distributed. $M R L(v)$ is $I D M R L$ for certain parameter values and $\operatorname{ECS}(p)$ is maximized either by market or hybrid lottery assignment (see Proposition 3 and Figure 2).

\subsection{Log-Logistic Distribution}

The survival and hazard rate functions of the log-logistic distribution are given by:

$$
F^{+}(v)=\frac{1}{1+(\alpha v)^{\beta}}, H R(v)=\frac{\alpha^{\beta} \beta v^{\beta-1}}{1+(\alpha v)^{\beta}}
$$

where $\alpha>0$ and $\beta>0$. Derivation of $M R L(v)$ yields:

$$
\operatorname{MRL}(v)=\frac{1+(\alpha v)^{\beta}}{\alpha \beta}\left[B\left(\frac{1}{\beta}, 1-\frac{1}{\beta}\right)-B_{F(v)}\left(\frac{1}{\beta}, 1-\frac{1}{\beta}\right)\right]
$$

where $F(v)=1-F^{+}(v), B(1 / \beta, 1-1 / \beta)$ is the beta function, $B_{F(v)}(1 / \beta, 1-1 / \beta)$ is the incomplete beta function, and $\mu=M R L(0)=B(1 / \beta, 1-1 / \beta) / \alpha \beta$ (see [11]). Despite the complexity of $M R L(v)$, if $\beta>1$, then $H R(v)$ is $I D H R$ and $\mu f(0)-1<$ 0 and therefore $M R L(v)$ is $D I M R L$.

To determine the optimal mechanism directly from $M R L(v)$ or indirectly from $H R(v)$ and $\mu$ (Proposition 2), and referencing Figure 1, if $M R L\left(v^{*}\right)>$ $\operatorname{MRL}\left(v_{\mu}\right)=\mu$, then $F^{+}\left(V^{*}\right)<F^{+}\left(v_{\mu}\right)$ and $\operatorname{ECS}(p)$ is maximized by selling $Q^{*}$ outright. If instead $\operatorname{MRL}\left(v^{*}\right)<\operatorname{MRL}\left(v_{\mu}\right)=\mu$, then $F^{+}\left(V^{*}\right)>F^{*}\left(v_{\mu}\right)$ and $\operatorname{ECS}(p)$ is maximized by pure lottery. $F^{+}\left(v_{\mu}\right)$ is calculated from (3) and (4) across a range of parameter values and compared against $F^{+}\left(V^{*}\right)=Q^{*} / N\left(\right.$ or $\left.N F^{+}\left(V^{*}\right)=Q^{*}\right)$ to determine from $M R L(V)$ whether market or pure lottery assignment is dominant.

For evaluation of Proposition 2, if $1 / H R\left(v^{*}\right)>1 / H R\left(v_{L}\right)=\mu$ and $H R^{\prime}\left(v^{*}\right)>0$, then $F^{*}\left(v^{*}\right)>F^{*}\left(v_{L}\right)$ and $M R L\left(v^{*}\right)<M R L(v)$ for $v \in\left[0, v^{*}\right)$. It follows that $\operatorname{ECS}(p)$ is maximized by allocating $Q^{*}$ by pure lottery. If instead $1 / H R\left(V^{*}\right)>1 / H R\left(v_{U}\right)=\mu$ and $H R^{\prime}\left(v^{*}\right)<0$, then $F^{*}\left(v_{U}\right)>F^{*}\left(v^{*}\right)$ and $\operatorname{MRL}\left(v^{*}\right)>M R L(v)$ for $v \in\left[0, v^{*}\right)$. Therefore, $E C S(p)$ is maximized by selling $Q^{*}$ outright. $F^{+}\left(v_{L}\right)$ and $F^{+}\left(v_{U}\right)$ are calculated and compared against $F^{+}\left(V^{*}\right)=Q^{*} / N$ to determine the relative scarcity or abundance of the good for the mechanism to be identified from $H R(v)$ and $\mu$.

The first half of Table 2 reports $F^{+}\left(v_{\mu}\right), F^{+}\left(v_{L}\right), F^{+}\left(v_{U}\right)$, and the Gini coefficient for the log-logistic distribution across a range of $(\alpha, \beta)$ values. The Gini coefficient indicates that individual private values become increasingly homogenous as $\beta$ increases from 1 . Considering $F^{*}\left(v_{\mu}\right)$, the results indicate $\lim _{\beta \rightarrow 0} F^{+}\left(v_{\mu}\right)=1$ and $\lim _{\beta \rightarrow 0} F^{+}\left(v_{\mu}\right)=0$. It follows that given the relative scarcity of the good, market (pure lottery) assignment will tend to dominate as $\beta \rightarrow 1(\beta \rightarrow \infty)$. For example, if $\beta \leq 2$ then $F^{*}\left(v_{\mu}\right) \geq 0.50$. Therefore, $\operatorname{MRL}\left({ }^{*}\right)>\mu$ and $\operatorname{ECS}\left(v^{*}\right)>$ $E C S(0)$ if $F^{+}\left(V^{*}\right)<0.50$. It follows that market assignment dominates pure lottery assignment if $Q^{*}$ is less than half of $N$. In contrast, if $\beta \geq 3$ then $F^{+}\left(v_{\mu}\right)<0.10$, so pure lottery assignment will dominate if $N$ is less than ten times greater than $Q *$. 
Table 2. Ranges of the Log-logistic and Beta Distributions for Maximizing $E C S(p)$ by Market, Pure Lottery, or Hybrid Lottery Assignment ${ }^{\mathrm{a}}$.

\begin{tabular}{|c|c|c|c|c|c|c|c|c|c|}
\hline \multicolumn{5}{|c|}{ Log-logistic Distribution } & \multicolumn{5}{|c|}{ Beta Distribution } \\
\hline \multicolumn{6}{|c|}{$\underline{\text { Proposition } 2}$} & \multicolumn{4}{|c|}{ Proposition 3} \\
\hline$(\alpha, \beta)$ & $F^{+}\left(v_{\mu}\right)$ & $F^{+}\left(v_{L}\right)$ & $F^{+}\left(v_{U}\right)$ & Gini & $(\alpha, \beta)$ & $F^{+}\left(V_{1}\right)$ & $F^{+}\left(v_{L}\right)$ & $F^{+}\left(V_{0}\right)$ & Gini \\
\hline$(0.5,1.5)$ & 0.92 & 0.98 & 0.16 & 0.67 & $(0.5,1.5)$ & 0.66 & 0.73 & 0.41 & 0.54 \\
\hline$(0.5,2.0)$ & 0.50 & 0.89 & 0.11 & 0.50 & $(0.5,2.0)$ & 0.58 & 0.69 & 0.35 & 0.56 \\
\hline$(0.5,2.5)$ & 0.21 & 0.85 & 0.05 & 0.40 & $(0.5,2.5)$ & 0.52 & 0.67 & 0.31 & 0.58 \\
\hline$(0.5,3.0)$ & 0.08 & 0.84 & 0.02 & 0.33 & $(0.5,3.0)$ & 0.47 & 0.65 & 0.27 & 0.59 \\
\hline$(0.5,3.5)$ & 0.03 & 0.85 & 0.01 & 0.29 & $(0.5,3.5)$ & 0.43 & 0.64 & 0.24 & 0.59 \\
\hline$(0.5,4.0)$ & 0.01 & 0.86 & 0.00 & 0.25 & $(0.5,4.0)$ & 0.39 & 0.63 & 0.22 & 0.60 \\
\hline
\end{tabular}

${ }^{\text {a }}$ From $F^{+}(v)=1-F(v)$, where $F(v)$ is the cumulative distribution function, $F^{+}\left(v_{\mu}\right)$ references $M R L\left(v_{\mu}\right)=\mu$; $F^{+}\left(v_{L}\right)$ references $1 / H R\left(v_{L}\right)=\mu$; similarly, $F^{+}\left(v_{U}\right)$ references $1 / H R\left(v_{U}\right)=\mu ; F^{+}\left(v_{0}\right)$ references $H R^{\prime}\left(v_{0}\right)=0$; and $F^{t}\left(v_{1}\right)$ references $M R L^{\prime}\left(v_{1}\right)=0$. The values and equalities also appear in Figure 1 and Figure 2 .

The results in Table 2 also identify the scarcity or abundance of $Q^{\star}$ needed for the optimal allocation mechanism to be determined from $H R(V)$ and $\mu$, as formalized in Proposition 2. From the columns labeled $F^{+}\left(V_{L}\right)$ and $F^{+}\left(V_{U}\right)$, if $Q^{*}$ and $N$ are such that $F^{+}\left(v^{*}\right)>0.84$ then $E C S(p)$ is maximized by pure lottery, whereas market assignment can be identified as the optimal mechanism if $Q^{*}$ is relatively scarce. For example, market assignment is optimal if $\beta \leq 2$ and $N$ exceeds $Q^{*}$ by at least tenfold $\left(F^{+}\left(V^{*}\right)<0.10\right)$. In general, the results in Table 2 indicate that if private values are log-logistic distributed with $\beta>1$, then evaluation of $\operatorname{HR}(v)$ and $\mu$ is sufficient to conclude market assignment will be superior if the agency has a small number of units to allocate over a large population of individuals.

\subsection{Beta Distribution}

In contrast to the log-logistic distribution, the upper bound of the beta distribution is finite and the survival and hazard rate functions do not appear in closed form. The functions may be written:

$$
F^{+}(v)=\frac{B(\alpha, \beta)-B_{v}(\alpha, \beta)}{B(\alpha, \beta)}, H R(v)=\frac{v^{\alpha-1}(1-v)^{\beta-1}}{B(\alpha, \beta)-B_{v}(\alpha, \beta)}
$$

where $\alpha>0$ and $\beta>0$, and $B(\alpha, \beta)$ and $B_{v}(\alpha, \beta)$ are the beta function and incomplete beta function, respectively. Derivation of $M R L(v)$ yields:

$$
\operatorname{MRL}(v)=\frac{\alpha}{\alpha+\beta} \frac{1-B_{v}(\alpha+1, \beta) / B(\alpha+1, \beta)}{1-B_{v}(\alpha, \beta) / B(\alpha, \beta)}-v
$$

where $\mu=\operatorname{MRL}(0)=\alpha /(\alpha+\beta)$. [15] showed that $H R(v)$ is $D I H R$ and $M R L(v)$ is $I D M R L$ for $\alpha<1$.

To determine the mechanism that maximizes $\operatorname{ECS}(p)$ directly from $M R L(v)$, and referencing Figure 2, note that $M R L(V)$ attains an interior maximum at $V_{1}$, so if $v_{1} \geq V^{*}$ then $F^{+}\left(V^{*}\right) \geq F^{+}\left(v_{1}\right)$ and $E C S(p)$ is maximized by market assignment of $Q^{*}$. If instead $v_{1}<V^{*}$ then $F^{+}\left(V^{*}\right)<F^{+}\left(v_{1}\right)$ and $E C S(p)$ is maximized by allocating $Q^{*}$ by hybrid lottery at price $p=V_{1} . F^{+}\left(V_{1}\right)$ is calculated from (5) and (6) across a 
range of parameter values and compared against $F^{+}\left({ }^{*}\right)=Q^{*} / N$ to determine from $M R L(V)$ whether market or hybrid lottery assignment is optimal.

For evaluating Proposition 3, if $1 / H R\left(\stackrel{*}{V^{*}}\right)<1 / H R\left(v_{L}\right)=\mu$ and $H R^{\prime}\left(v^{*}\right)<0$, then $F^{+}(\stackrel{*}{v})>F^{+}\left(v_{L}\right)$ and $\operatorname{MRL}\left(\stackrel{v}{v}^{*}\right)>M R L(v)$ for $v \in\left[0, v_{v}^{*}\right)$. It follows that $\operatorname{ECS}(p)$ is maximized by selling $Q^{*}$ outright. If instead $1 / H R\left({ }^{*}\right)<1 / H R\left(v_{0}\right)$ and $H R^{\prime}(v)>0$, then $F^{\dagger}\left(v^{*}\right)<F^{\dagger}\left(v_{0}\right)$ and $M R L\left(v^{*}\right)<M R L(v)$ for $v \in\left[0, v^{*}\right) . E C S(p)$ is therefore maximized by allocating $Q^{*}$ by hybrid lottery. $F^{+}\left(v_{L}\right)$ and $F^{+}\left(v_{0}\right)$ are calculated from (5) and (6) and compared against $F^{+}\left(V^{*}\right)$ to determine the relative scarcity or abundance of the good for the optimal mechanism to be identified from $H R(v)$ and $\mu$.

The second half of Table 2 reports $F^{+}\left(v_{1}\right), F^{+}\left(v_{L}\right), F^{+}\left(v_{0}\right)$, and the Gini coefficient across a range of $(\alpha, \beta)$ values $^{6}$. In contrast to the log-logistic distribution, the homogeneity of individual private values is relatively constant across the cases considered as indicated by the Gini coefficients. Referencing $F^{+}\left(v_{1}\right)$, the results indicate the interior maximum of $M R L(V)$ is located well within the upper and lower bounds of the distribution, with $F^{+}\left(V_{1}\right)$ ranging from 0.66 to about 0.40. As $E C S(p)$ is maximized by hybrid lottery assignment at price $p=V_{1}$ if $F^{+}\left(v_{1}\right)>F^{+}(\stackrel{*}{v})$ and by market assignment at $p=v^{*}$ if $F^{+}\left(v_{1}\right) \leq F^{+}(\stackrel{*}{v})$, it follows that across the cases reported in Table 2 the hybrid lottery is optimal if $Q^{*}$ is less than fourth tenths of $N$ and market assignment is optimal if $Q^{*}$ is at least two thirds as large as $N$.

The results in Table 2 also identify the relative scarcity or abundance of $Q^{*}$ needed for the optimal allocation mechanism to be determined from $H R(v)$ and $\mu$, as formalized in Proposition 3. As $F^{+}\left(V_{L}\right)$ ranges from 0.73 to 0.63 and $F^{+}\left(v_{0}\right)$ ranges from about 0.40 to 0.22 , it follows that allocation of $Q^{*}$ by hybrid lottery is optimal over all cases in Table 2 if $F^{+}\left(V^{*}\right)<0.22$, or $N$ is at least five times greater than $Q^{*}$, whereas market assignment is optimal if $F^{+}\left(V^{*}\right)>0.73$, or $Q^{*}$ is at least three-fourths as large as $N$. Overall, in settings in which the agency has a limited number of units to be allocated over a large population of individuals, if private values are beta distributed with $\alpha<1$, then the expected consumer surplus from screening low-valued individuals by posting a non-zero price and assigning units by lottery will exceed that resulting from selling the units outright.

\section{Conclusions}

This paper contributes to the growing body of literature investigating the performance, merits, and shortcomings of non-market allocating mechanisms against market-based benchmarks. A framework was developed for characterizing optimal posted-price mechanisms for a public agency confronted with the problem of allocating units of an indivisible good or service under the utilitarian distributional objective of maximizing aggregate expected consumer surplus. From a setting of symmetric independent individual private valuations and survival function representations of individual and aggregate demand, the optimal

${ }^{6}$ The Gini coefficient of the beta distribution is given by $(\alpha / 2) B(\alpha+\beta, \alpha+\beta) /(B(\alpha, \alpha) B(\beta, \beta))$. 
allocation mechanism could be determined from direct evaluation of the value distribution's mean residual value function or indirectly from the hazard rate and [9]'s eta function.

Monotonicity of any of the three functions was shown to be sufficient to identify either market assignment or pure lottery assignment as being optimal, whereas information on the relative scarcity or abundance of the good may or may not be necessary to determine the optimal mechanism and degree of underpricing for the non-monotonic classes of the functions. The results also provide a simple means by which to determine the optimal mechanism given distributional assumptions regarding individual private valuations and allow for direct comparison to outcomes in the design literature established in terms of the hazard rate function. The current work can be extended in several dimensions, two of which include the introduction of a revenue target for the agency and the characterization of the optimal mechanism when units of the good can be partitioned and allocated through a mixture of market and non-market mechanisms.

\section{Acknowledgements}

I am grateful for the helpful comments on an earlier version of the work by seminar participants at the University of Central Florida and by an anonymous reviewer. Any errors are my own.

\section{References}

[1] Barzel, Y. (1974) A Theory of Rationing by Waiting. The Journal of Law and Economics, 17, 73-95. http://www.jstor.org/stable/724744

[2] Holt, C.A. and Sherman, R. (1982) Waiting-Line Auctions. Journal of Political Economy, 90, 280-294. http://www.jstor.org/stable/1830293

[3] Boyce, J.R. (1994) Allocation of Goods by Lottery. Economic Inquiry, 32, 457-476. https://doi.org/10.111/j.1465-7295.1994.tb01343.x

[4] Taylor, G.A., Tsui, K.K. and Zhu, L. (2003) Lottery or Waiting-line Auction? Journal of Public Economics, 87, 1313-1334. https://dx.doi.org/10.1016/S0047-2727(01)00196-7

[5] Koh, W.T.H., Yang, Z. and Zhu, L. (2006) Lottery Rather than Waiting-Line Auction. Social Choice and Welfare, 27, 289-310. https://doi.org/10.1007/s00355-006-0134-y

[6] Yoon, K. (2011) Optimal Mechanism Design When Both Allocative Inefficiency and Expenditure Inefficiency Matter. Journal of Mathematical Economics, 47, 670-676. https://dx.doi.org/10.1016/j.jmateco.2011.09.002

[7] Condorelli, D. (2013) Market and Non-Market Mechanisms for the Optimal Allocation of Scarce Resources. Games and Economic Behavior, 82, 582-591. https://dx.doi.org/10.1016/j.geb.2013.08.008

[8] Chakravarty, S. and Kaplan, T.R. (2013) Optimal Allocation without Transfer Payments. Games and Economic Behavior, 77, 1-20. https://dx.doi.org/10.1016/j.geb.2012.08.006

[9] Glaser, R.E. (1980) Bathtub and Related Failure Rate Characterizations. Journal of the American Statistical Association, 75, 667-672.

[10] Bulow, J. and Klemperer P. (2012) Regulated Prices, Rent Seeking, and Consumer 
Surplus. Journal of Political Economy, 120, 160-186.

[11] Lai, C.D. and Xie, M. (2006) Stochastic Ageing and Dependence for Reliability. Springer Science+ Business Media, Inc., New York.

[12] Marshall, A.W. and Olkin, I. (2007) Life Distributions: Structure of Nonparametric, Semiparametric and Parametric Families. Springer Science + Business Media, LLC, New York.

[13] Bryson, M.C. and Siddiqui, M.M. (1969) Some Criteria for Aging. Journal of the American Statistical Association, 64, 1472-1483.

[14] Gupta, R.C. and Akman, H.O. (1995) Mean Residual Life Functions for Certain Types of Non-monotonic Ageing. Communications in Statistics-Stochastic Models, 11, 219-225. https://dx.doi.org/10.1080/15326349508807340

[15] Ghitany, M.E. (2004) The Monotonicity of the Reliability Measures of the Beta Distribution. Applied Mathematics Letters, 17, 1277-1283.

https://dx.doi.org/10.1016/j.aml.2003.12.007

[16] Bradley, D.M. and Gupta, R.C. (2003) Limiting Behavior of the Mean Residual Life Function. Annals of the Institute of Statistical Mathematics, 55, 217-226.

[17] Bagnoli, M. and Bergstrom T. (2005) Log-Concave Probability and Its Applications. Economic Theory, 26,445-469. https://doi.org/10.1007/s00199-004-514-4

Submit or recommend next manuscript to SCIRP and we will provide best service for you:

Accepting pre-submission inquiries through Email, Facebook, LinkedIn, Twitter, etc. A wide selection of journals (inclusive of 9 subjects, more than 200 journals) Providing 24-hour high-quality service User-friendly online submission system Fair and swift peer-review system Efficient typesetting and proofreading procedure Display of the result of downloads and visits, as well as the number of cited articles Maximum dissemination of your research work

Submit your manuscript at: http://papersubmission.scirp.org/

Or contact tel@scirp.org 